\title{
Accelerometry and heart rate as a measure of physical fitness: cross-validation
}

Citation for published version (APA):

Plasqui, G., \& Westerterp, K. R. (2006). Accelerometry and heart rate as a measure of physical fitness: cross-validation. Medicine and Science in Sports and Exercise, 38(8), 1510-1514.

https://doi.org/10.1249/01.mss.0000228942.55152.84

Document status and date:

Published: 01/01/2006

DOI:

10.1249/01.mss.0000228942.55152.84

Document Version:

Publisher's PDF, also known as Version of record

Document license:

Taverne

Please check the document version of this publication:

- A submitted manuscript is the version of the article upon submission and before peer-review. There can be important differences between the submitted version and the official published version of record.

People interested in the research are advised to contact the author for the final version of the publication, or visit the DOI to the publisher's website.

- The final author version and the galley proof are versions of the publication after peer review.

- The final published version features the final layout of the paper including the volume, issue and page numbers.

Link to publication

\footnotetext{
General rights rights.

- You may freely distribute the URL identifying the publication in the public portal. please follow below link for the End User Agreement:

www.umlib.nl/taverne-license

Take down policy

If you believe that this document breaches copyright please contact us at:

repository@maastrichtuniversity.nl

providing details and we will investigate your claim.
}

Copyright and moral rights for the publications made accessible in the public portal are retained by the authors and/or other copyright owners and it is a condition of accessing publications that users recognise and abide by the legal requirements associated with these

- Users may download and print one copy of any publication from the public portal for the purpose of private study or research.

- You may not further distribute the material or use it for any profit-making activity or commercial gain

If the publication is distributed under the terms of Article $25 \mathrm{fa}$ of the Dutch Copyright Act, indicated by the "Taverne" license above, 


\title{
Accelerometry and Heart Rate as a Measure of Physical Fitness: Cross-Validation
}

\author{
GUY PLASQUI and KLAAS R. WESTERTERP \\ Department of Human Biology, Maastricht University, THE NETHERLANDS
}

\begin{abstract}
PLASQUI, G., and K. R. WESTERTERP. Accelerometry and Heart Rate as a Measure of Physical Fitness: Cross-Validation. Med. Sci. Sports Exerc., Vol. 38, No. 8, pp. 1510-1514, 2006. Purpose: We recently reported on a new method to assess physical fitness, based on the combined use of accelerometry and heart rate (HR) registration. This study tested the validity of the prediction formula in a group of healthy young adults. Methods: Twenty-six healthy subjects performed a maximal incremental test on a bicycle ergometer to determine $\mathrm{V}_{2 \max }$. A triaxial accelerometer and a HR monitor were worn for $7 \mathrm{~d}$ under free-living conditions. The prediction formula developed in a previous experimental group (EXP) was applied on the cross-validation group (CV). Results: No difference was found in subjects' characteristics between the EXP and CV groups except for accelerometer output (activity counts). Although measured $\dot{\mathrm{V}}_{2 \max }$ could be predicted for $80 \%(P<0.0001)$, a paired $t$-test showed a significant difference between measured and predicted $\dot{\mathrm{V}} \mathrm{O}_{2 \max }\left(178 \mathrm{~mL} \cdot \mathrm{min}^{-1} ; P=0.015\right)$. Because of the difference in activity between the EXP and the $\mathrm{CV}$ groups, all data were combined and sorted according to activity counts, then two new groups were formed. As a result, EXP and CV groups were created that did not significantly differ in activity or any other parameters. The formula developed in the new experimental group $\left(R^{2}=0.74\right.$; $P<0.0001)$ explained $72 \%(P<0.0001)$ of the variation in $\mathrm{V}_{2 \max }$ in the cross-validation group, a paired $t$-test showed no difference between measured and predicted $\dot{V O}_{2 \max }$, and Bland-Altman plotting showed no systematic bias. Conclusion: Although a good correlation was seen between measured and predicted $\dot{\mathrm{V}}_{2 \max }$ in the cross-validation group, care should be taken in applying the prediction formula on groups that differ in physical activity from the current study population. Key Words: MAXIMAL OXYGEN UPTAKE, TRIAXIAL ACCELEROMETER, BODY COMPOSITION, SUBMAXIMAL EXERTION, DAILY LIFE
\end{abstract}

$\mathrm{M}$ aximal oxygen uptake $\left(\dot{\mathrm{V}}_{2 \max }\right)$, the most widely used measure of physical fitness, is inversely related with several health outcomes, such as cardiovascular disease and coronary artery disease (25). $\dot{\mathrm{VO}}_{2 \max }$ can be accurately measured in a laboratory setting using standardized protocols that require sophisticated equipment and maximal exertion of the subject. The physiological importance of $\dot{\mathrm{V}}_{2 \max }$ as a measure of aerobic fitness, as an indication of physical activity, and as a health parameter has led to the development of various maximal and submaximal field tests to estimate $\dot{\mathrm{V}}_{2 \max }$ $(1,4,8,11,14,18,21)$. Although useful for research purposes, these tests are limited in their applicability for personal assessment by exertion level and the requirements for specific procedures.

Weyand et al. (24) developed a fitness index by the combined use of foot-ground contact times and heart rate (HR) monitoring during running on a treadmill. The fitness index correlated well $(\mathrm{r}=0.90)$ with $\dot{\mathrm{VO}}_{2 \max }$, and the

Address for correspondence: Guy Plasqui, Department of Human Biology, Maastricht University, PO Box 616, 6200 MD Maastricht, The Netherlands; E-mail: g.plasqui@hb.unimaas.nl.

Submitted for publication February 2005.

Accepted for publication March 2006.

0195-9131/06/3808-1510/0

MEDICINE \& SCIENCE IN SPORTS \& EXERCISE E $_{\circledast}$

Copyright $(2006$ by the American College of Sports Medicine

DOI: $10.1249 / 01 . m s s .0000228942 .55152 .84$ predictive power was independent of running speed. Although this fitness index is a promising tool to assess physical fitness, its usefulness is limited to a laboratory test on a treadmill, and it has not been tested in the field at volitional running or (more desirably) walking speeds.

Most submaximal protocols are based on the inverse relationship between HR at a given exercise intensity and physical fitness; that is, when the intensity of a certain activity is known and $\mathrm{HR}$ is registered, $\mathrm{VO}_{2 \max }$ can be predicted. Developing a fitness index for application in daily life requires a tool that will estimate the intensity of different activities.

We recently reported on a new fitness index that was based on the combined use of accelerometry and HR registration and that could be used in daily life without requiring a specific protocol (22). When the output of the accelerometer (activity counts per minute) was used to define the intensity of the activity performed (23) (i.e., the average intensity over the monitoring time was used), the corresponding HR would be inversely related with physical fitness. Multiple regression analysis showed that this fitness index, defined as HR over activity counts per minute $\left(\mathrm{HR} \cdot \mathrm{ACM}^{-1}\right)$, contributed significantly (additional explained variation from fitness index beyond that of age, gender, and body mass (BM) was $9 \%$, partial $\mathrm{R}=$ $-0.48, P=0.02)$ to the explained variation in $\dot{\mathrm{V}}_{2 \max }$. The present study was designed to validate the prediction equation in a group of healthy subjects with varying degrees of physical fitness. 


\section{SUBJECTS AND METHODS}

Subjects. Subjects were 26 healthy adults between the ages of 18 and $50 \mathrm{yr}$, most of them recruited from the university. Information about the protocol of the study was provided, informed written consent was obtained, and the study was approved by the ethics committee of Maastricht University. This group will be referred to as the crossvalidation $\left(\mathrm{CV}_{1}\right)$ group. The experimental $\left(\mathrm{EXP}_{1}\right)$ group used to develop the prediction formula has been described in a previous study (22). Physical characteristics of the $\mathrm{CV}_{1}$ group and the $\mathrm{EXP}_{1}$ group are presented in Table 1 .

Maximal aerobic power. $\dot{\mathrm{V}}_{2 \max }$ was determined during an incremental test on a cycle ergometer according to the protocol of Kuipers et al. (12). After a warm-up of $5 \mathrm{~min}$ at $100 \mathrm{~W}$ for men and $75 \mathrm{~W}$ for women, workload was increased by $50 \mathrm{~W}$ every $2.5 \mathrm{~min}$. When HR reached a value of $35 \mathrm{bpm}$ below the age-predicted maximal HR (220 bpm - age) or the respiratory quotient (RQ) exceeded 1 , workload was increased by $25 \mathrm{~W}$ every $2.5 \mathrm{~min}$ until exhaustion. Subjects were equipped with a mouthpiece and nose clip, and expired air was continuously analyzed for $\mathrm{O}_{2}$ consumption and $\mathrm{CO}_{2}$ production (Oxycon- $\beta$, Bunnik, The Netherlands). During the latter stages of the test, each subject was verbally encouraged by the test operators to give a maximal effort. Achievement of $\dot{\mathrm{V}}_{2 \max }$ was accepted if two of three of the following conditions were met: subject's respiratory exchange ratio (RER) was $>1.1$, maximal HR was $>85 \%$ of age-predicted maximal HR (220 - age), or the $\dot{\mathrm{VO}}_{2}$ curve showed a leveling off. Because most of the subjects were already familiar with the protocol, these criteria were met by all subjects.

Anthropometrics. Body mass was determined to the nearest $0.1 \mathrm{~kg}$ (SECA, model 707, Hamburg, Germany) before the bicycle ergometer test, with subjects in light sports clothing and without shoes.

Accelerometry. The triaxial accelerometer for movement registration (Tracmor; Philips Research, Eindhoven, The Netherlands) was used to register daily life activity. The accelerometer was worn consecutively for $7 \mathrm{~d}$ during waking hours, except during water activities. The accelerometer is worn at the lower back by means of an elastic belt. It registers accelerations in the anteroposterior, mediolateral, and longitudinal axes of the trunk. Data were collected and stored minute by minute and downloaded to computer files, and the sum of all three axes was used as

TABLE 1. Subject characteristics of experimental group 1 (EXP $\left.{ }_{1}\right)$ (22) and crossvalidation $1\left(\mathrm{CV}_{1}\right)$ group. Values are mean $\pm \mathrm{SD}$.

\begin{tabular}{lcc}
\hline & EXP $_{\mathbf{1}}$ & CV $_{\mathbf{1}}$ \\
\hline$N(\mathrm{M} / \mathrm{F})$ & $25(10 / 15)$ & $26(14 / 12)$ \\
Age $(\mathrm{yr})$ & $28 \pm 7$ & $29 \pm 6$ \\
Body mass $(\mathrm{kg})$ & $68.3 \pm 12.6$ & $71.2 \pm 12.0$ \\
Body mass index $\left(\mathrm{kg} \cdot \mathrm{m}^{-2}\right)$ & $23.1 \pm 3.2$ & $22.7 \pm 2.7$ \\
Activity counts (counts per minute) & $478 \pm 117$ & $394 \pm 89^{\star}$ \\
$\mathrm{HR} \cdot \mathrm{ACM}^{-1}$ (beats per activity count) & $0.19 \pm 0.05$ & $0.21 \pm 0.05$ \\
$\dot{\mathrm{V}}{ }_{2 \max }\left(\mathrm{mL} \cdot \mathrm{min}^{-1}\right)$ & $2975 \pm 696$ & $3177 \pm 752$ \\
\hline
\end{tabular}

* Significant difference between groups $(P=0.006)$. HR.ACM ${ }^{-1}$, heart rate over activity counts per minute.

Values are mean $\pm \mathrm{SD}$ the activity measure. Tracmor output is defined as activity counts per minute (ACM).

Heart rate monitoring. Heart rate was continuously registered for seven consecutive days using a Polar (S610i) HR monitor (Polar Electro Oy, Kempele, Finland). Subjects were instructed on how to use the transmitter belt and the wristwatch and were asked to wear the monitor at the same time as the accelerometer (i.e., waking hours, except during water activities). The HR monitor was programmed to store heartbeat every minute, allowing synchronization in time with the accelerometer. After $7 \mathrm{~d}$, the data were downloaded to computer files.

Fitness index. The accelerometer and HR monitor, both programmed to provide one data point each minute, were synchronized in time. The data of all $7 \mathrm{~d}$ were combined as one dataset. When the HR monitor generated inaccurate data (because of flawed contact of the transmitter belt with the skin or telemetric interference from other electric devices) the corresponding accelerometer value was also removed. On average, $740 \mathrm{~min} \cdot \mathrm{d}^{-1}$ were used to establish the fitness index. For each subject, one average value (over the entire 7-d registration) was calculated for both ACM and HR (bpm). The ratio of $\mathrm{HR} \cdot \mathrm{ACM}^{-1}$ was then used as our fitness index (22).

Comparison of EXP and CV group. Student's $t$-test for unpaired data was used to compare the $\mathrm{EXP}_{1}$ with the $\mathrm{CV}_{1}$ group. A significant difference for activity counts $(P=$ 0.006 ) was found (the $\mathrm{EXP}_{1}$ group was significantly more active than the $\mathrm{CV}_{1}$ group) (Table 1). Therefore, subjects from both the $\mathrm{EXP}_{1}$ and the $\mathrm{CV}_{1}$ groups were combined $(N=51)$ and sorted for activity counts. Two new groups were formed by coding all odd numbers 0 and even numbers 1 , creating a new EXP group and CV group that did not differ in physical activity. These groups will be referred to as $\mathrm{EXP}_{2}$ and $\mathrm{CV}_{2}$. Characteristics of the $\mathrm{EXP}_{2}$ and $\mathrm{CV}_{2}$ groups are presented in Table 2. Student's $t$-test for unpaired data showed no significant differences in any of the parameters between groups (Table 2).

Statistics. Both the EXP and CV groups were compared using Student's $t$-test for unpaired data. Multiple linear regression was used to develop the prediction formula in $\mathrm{EXP}_{2}$. In the CV groups, Student's $t$-test for paired data was used to test differences between predicted (equations developed in EXP groups) and measured $\dot{\mathrm{V}} \mathrm{O}_{2 \text { max }}$. Assuming that a mean difference $\pm \mathrm{SD}$ of $300 \pm$ $400 \mathrm{~mL} \cdot \min ^{-1}\left(\sim 10 \%\right.$ of the average $\left.\dot{\mathrm{VO}}_{2 \max }\right)$ would be a physiologically and methodologically significant

TABLE 2. Subject characteristics of experimental group $2\left(\mathrm{EXP}_{2}\right)$ and cross-validation group $2\left(C_{2}\right)$ after stratification for physical activity. Values are mean $\pm S D$.

\begin{tabular}{lcc}
\hline & EXP $_{\mathbf{2}}$ & $\mathbf{C V}_{\mathbf{2}}$ \\
\hline$N(\mathrm{M} / \mathrm{F})$ & $26(10 / 16)$ & $25(14 / 11)$ \\
Age $(\mathrm{yr})$ & $28 \pm 6$ & $30 \pm 7$ \\
Body mass $(\mathrm{kg})$ & $69.6 \pm 11.2$ & $70.0 \pm 13.5$ \\
Body mass index $\left(\mathrm{kg} \cdot \mathrm{m}^{-2}\right)$ & $22.7 \pm 2.7$ & $23.6 \pm 4.2$ \\
Activity counts (counts per minute) & $439 \pm 125$ & $432 \pm 97$ \\
$\mathrm{HR} \cdot \mathrm{ACM}^{-1}$ (beats per activity count) & $0.20 \pm 0.06$ & $0.20 \pm 0.05$ \\
$\dot{\mathrm{V}} \mathrm{O}_{2 \mathrm{max}}\left(\mathrm{mL} \cdot \mathrm{min}^{-1}\right)$ & $3054 \pm 643$ & $3103 \pm 814$ \\
\hline $\mathrm{HR}_{\mathrm{ACM}}{ }^{-1}$, heart rate over activity counts per minute.
\end{tabular}

Medicine \& Science in Sports \& Exercise ${ }_{\circledast}$ 
difference with 25 subjects, we had a power of 0.95 to detect such a difference. Linear regression was used to test agreement between predicted and measured $\dot{\mathrm{V}}_{2 \max }$. Bland-Altman plotting (2) and linear regression were used to detect systematic differences between measured and predicted $\dot{\mathrm{VO}}_{2 \max }$. All analyses were done with Statview 5.0 for Macintosh (SAS Institute Inc., NC) and SPSS 10.0 for Macintosh (SPSS Inc., Chicago, IL). The level for statistical significance was set at $P<0.05$.

\section{RESULTS}

$\mathbf{E X P}_{\mathbf{1}}$ and $\mathbf{C V}_{\mathbf{1}}$. Predicted $\dot{\mathrm{VO}}_{2 \max }$ (equation 1) correlated well with measured $\dot{\mathrm{V}}_{2 \max }(\mathrm{R}=0.90, P<0.0001)$, and the standard error of estimate (SEE, square root of the average squared error of prediction) was $341 \mathrm{~mL} \cdot \mathrm{min}^{-1}$, or $10.7 \%$ of the average $\dot{\mathrm{VO}}_{2 \max }$. Predicted $\dot{\mathrm{VO}}_{2 \max }$ was $178 \pm$ 349 (mean $\pm \mathrm{SD}) \mathrm{mL} \cdot \mathrm{min}^{-1}$, or $5.6 \%$ lower than measured $(P=0.015)$. Bland-Altman plotting and linear regression showed a significant positive relation $(P=0.007)$ between the average of predicted and measured $\mathrm{V}_{2 \max }$ and the difference between both (Fig. 1).

$$
\begin{aligned}
\dot{\mathrm{V}}_{2 \max }= & 2714-31.48 * \text { age }+592 * \text { gender }+25.46 * \mathrm{BM} \\
& -4401 * \mathrm{HR}^{\mathrm{ACCM}}{ }^{-1}
\end{aligned}
$$

where age is in years, gender $=0$ for women and 1 for men, $\mathrm{BM}$ is body mass in kilograms, and $\mathrm{HR} \cdot \mathrm{ACM}^{-1}$ is the fitness index defined as HR over activity counts per minute.

$\mathbf{E X P} \mathbf{P}_{\mathbf{2}}$ and $\mathbf{C V}_{\mathbf{2}}$. The same independent variables as in equation 1 were used to predict $\mathrm{VO}_{2 \max }$ in the $\mathrm{EXP}_{2}$ group. $\mathrm{BM}$, age, gender, and $\mathrm{HR} \cdot \mathrm{ACM}^{-1}$ significantly contributed to the prediction of $\dot{\mathrm{V}} \mathrm{O}_{2 \max }$ and resulted in a total explained variation of $74 \%$ with a SEE of $358 \mathrm{~mL} \cdot \mathrm{min}^{-1}$ or $11.7 \%$. The additional explained variance by the fitness index beyond that from BM, age, and gender was $15 \%(P=$ $0.003)$. In comparison, when only activity counts were used in the analysis instead of the fitness index, the total explained variation was $71 \%$, and the SEE was $374 \mathrm{~mL}$. $\min ^{-1}$, or $12.2 \%$. Regression coefficients with standard

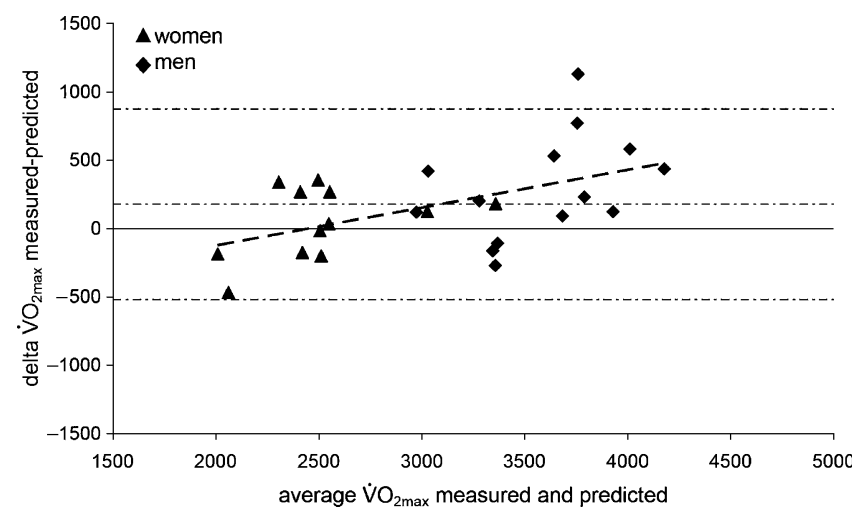

FIGURE 1-Bland-Altman plot for cross-validation group $1\left(\mathrm{CV}_{1}\right)$ : mean $\dot{V}_{2 \max }$ (measured and predicted) plotted against the difference (measured vs predicted) in $\mathrm{VO}_{2 \max }$. The striped line shows the significant positive relation $(P=0.007)$. Mean difference and $95 \%$ limits of agreement (mean \pm 2SD) are indicated with a dashed line. error, significance levels, and correlations are presented in Table 3. When this prediction equation (equation 2) was used on $\mathrm{CV}_{2}$, the correlation with measured $\dot{\mathrm{VO}}_{2 \max }$ was $0.85(P<0.0001)$, and the SEE was $437 \mathrm{~mL} \cdot \mathrm{min}^{-1}$, or $14.1 \%$. No significant difference was found between measured and predicted $\dot{\mathrm{V}}_{2 \max }\left(32 \pm 429 \mathrm{~mL} \cdot \mathrm{min}^{-1}\right)$, and Bland-Altman plotting and linear regression no longer showed a significant relation between the average of predicted and measured $\dot{\mathrm{V}}_{2 \max }$ and the difference between both (Fig. 2).

$$
\begin{aligned}
\dot{\mathrm{VO}}_{2 \max }= & 2938-38.46^{*} \text { age }+563^{*} \text { gender }+27.66^{*} \mathrm{BM} \\
& -4842^{*} \mathrm{HR} \cdot \mathrm{ACM}^{-1}
\end{aligned}
$$

where age is in years, gender $=0$ for women and 1 for men, $\mathrm{BM}$ is body mass in kilograms, and $\mathrm{HR} \cdot \mathrm{ACM}^{-1}$ is the fitness index defined as HR over activity counts per minute.

\section{DISCUSSION}

This study tested the validity of our fitness index to predict $\dot{\mathrm{V}}_{2 \max }$ in a sample of healthy, normal-weight subjects with a wide range of physical activity and fitness. In $\mathrm{CV}_{1}$, equation 1 resulted in a total explained variation in $\mathrm{V}_{2 \max }$ of $81 \%$ with a SEE of $10.7 \%$. In $\mathrm{CV}_{2}$, equation 2 predicted $\dot{\mathrm{VO}}_{2 \max }$ for $72 \%$ with a SEE of $14.1 \%$.

In our previous study (22), an equation was developed to predict $\mathrm{VO}_{2 \max }$ from $\mathrm{BM}$, age, gender, and the fitness index $\mathrm{HR} \cdot \mathrm{ACM}^{-1}$. The number of subjects, however, was too small to create an EXP and a CV group. In this study, we attempted to create a $\mathrm{CV}$ group with characteristics comparable to those of the EXP group. However, a significant difference in physical activity existed between groups. Regression analysis showed very good correlation $(\mathrm{R}=0.90)$ between predicted and measured $\mathrm{V}_{2 \max }$, but a systematic difference was seen between predicted and measured $\dot{\mathrm{VO}}_{2 \max }$ of $5.6 \%$. Furthermore, Bland-Altman plotting showed an overprediction of $\dot{\mathrm{VO}}_{2 \max }$ at the lower fitness levels and an underprediction at the higher levels. To test whether this was caused by the difference in physical activity, all subjects were combined, sorted for physical activity, and new EXP and CV groups were created. This technique has been applied by other authors (24). Although equation 2 resulted in a slightly lower correlation $(\mathrm{R}=0.85)$ and larger SEE $(14.1 \%)$ in the $\mathrm{CV}$ group, a systematic bias was not found between predicted and measured $\dot{\mathrm{V}}_{2 \max }$ as indicated by BlandAltman plotting.

The practical utility of various protocols to predict $\dot{\mathrm{V}}_{2 \max }$ can be questioned based on three main considerations: accuracy and validity of the prediction, ease and convenience of the protocol, and generalized application to a broad population. Accuracy and validity of a prediction equation should be evaluated by the correlation coefficient and the SEE in both the EXP and CV groups and by investigating systematic differences between predicted and measured $\mathrm{VO}_{2 \max }$. Field tests requiring maximal exertion resulted in good to very good correlations $(4,14)$. Cooper $(4)$ 
TABLE 3. Multiple regression analysis with $\dot{\mathrm{V}}_{2 \max }$ as the dependent variable and age, gender, BM, and $\mathrm{HR} \cdot \mathrm{ACM}^{-1}$ as the independent variables. Data from experimental group 2 $\left(\mathrm{EXP}_{2}\right)$.

\begin{tabular}{|c|c|c|c|c|c|c|}
\hline \multirow[b]{2}{*}{$\dot{\mathrm{V}}_{2 \max }$} & \multirow[b]{2}{*}{ Coefficients } & \multirow[b]{2}{*}{ SE } & \multirow[b]{2}{*}{$P$} & \multicolumn{3}{|c|}{ Correlations (R) } \\
\hline & & & & Zero-Order* & Partial $^{\dagger}$ & Part $^{\dagger+}$ \\
\hline Constant & 2938 & 596 & $<0.0001$ & & & \\
\hline Age (yr) & -38.46 & 13.92 & 0.01 & 0.07 & -0.50 & -0.30 \\
\hline Gender & 563 & 185 & 0.006 & 0.67 & 0.55 & 0.35 \\
\hline Body mass (kg) & 27.66 & 7.75 & 0.002 & 0.54 & 0.58 & 0.38 \\
\hline $\mathrm{HR} \cdot \mathrm{ACM}^{-1}$ (beats per activity count) & -4842 & 1417 & 0.003 & -0.49 & -0.60 & -0.39 \\
\hline \multirow[t]{2}{*}{ Model } & & SEE & & & & \\
\hline & & 358 & $<0.0001$ & & $R=0.86$ & \\
\hline
\end{tabular}

Gender: women $=0$, men $=1$; HR.ACM ${ }^{-1}$, heart rate over activity counts per minute; SEE, standard error of estimate (square root of the average squared error of prediction).

* The zero-order correlation is the simple (Pearson) correlation between the dependent and the independent variable.

t The partial correlation is the correlation between the dependent and an independent variable when the linear effects of the other independent variables in the model have been removed from both.

$\mathrm{t \dagger}^{+}$The part (semipartial) correlation is the correlation between the dependent and an independent variable when the linear effects of the other independent variables in the model have been removed from the independent variable only.

reported a correlation of 0.90 between the 12-min performance test and measured $\dot{\mathrm{V}}_{2 \max }$, but did not provide information about the SEE, and no cross-validation was included. Attempts by other authors to validate this field test resulted in correlations ranging from $\mathrm{R}=0.13$ to 0.90 (11). Various submaximal tests have yielded correlations ranging from $\mathrm{R}=0.46$ to 0.95 (11). Many of these tests do not present cross-validation results $(6,10,19)$, require sophisticated laboratory equipment $(3,6,19)$, and do not provide a measure of the $\operatorname{SEE}(5,9,17,20)$. When crossvalidating a prediction equation, the use of SEE in addition to correlation coefficients is preferred, and mean values of measured and predicted should be comparable (16). George et al. found SEE of 6.5 and $7.5 \%$ for a submaximal treadmill jogging test (7) and a 1-mile track jog (8), respectively, both in fit, college-aged individuals. Kline et al. (11) reported a SEE of $12.6 \%$ in the CV group for a 1-mile track walk. Naughton et al. (20) validated the Canadian (13) and the European (15) versions of the 20-m shuttle run test in school children and found an underestimation of $\dot{\mathrm{V}}_{2 \max }$ of $7.7 \%$ for the European version and an overestimation of $11.4 \%$ for the Canadian version. No estimate of the SEE was provided. Weyand et al. (24) developed a fitness index based on foot-ground contact

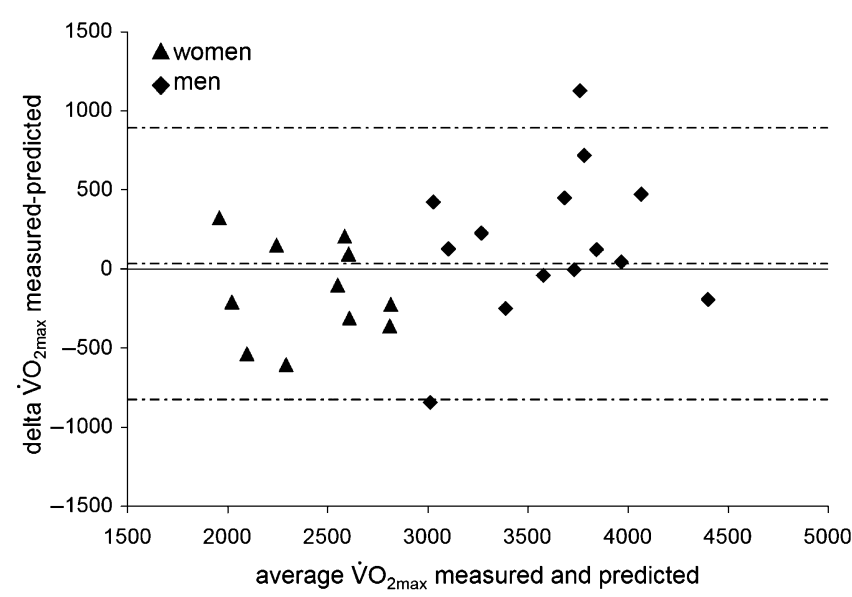

FIGURE 2-Bland-AItman plot for cross-validation group $2\left(\mathrm{CV}_{2}\right)$ : mean $\dot{\mathrm{V}} \mathrm{O}_{2 \max }$ (measured and predicted) plotted against the difference (measured vs predicted) in $\mathrm{VO}_{2 \max }$. Mean difference and $95 \%$ limits of agreement (mean \pm 2SD) are indicated with a dashed line. times and HR during treadmill running. The theoretic model of their fitness index is probably the most closely related to our fitness index, although they did not use a field setting. They found a correlation of $\mathrm{R}=0.84$ between predicted and measured in the CV group, but no SEE was provided. They did find a systematic difference between measured and predicted $\dot{\mathrm{VO}}_{2 \max }$ of $8.3 \%$ (24). Our equation 1 resulted in a SEE of $10.7 \%$, but a systematic difference existed between measured and predicted $\dot{\mathrm{V}} \mathrm{O}_{2 \max }$, whereas equation 2 resulted in a slightly higher SEE (14.1\%), but without systematic bias. In addition, a Bland-Altman plot showed a positive correlation in $\mathrm{CV}_{1}$ but not in $\mathrm{CV}_{2}$. The higher $\mathrm{SEE}$ in $\mathrm{CV}_{2}$ was mainly explained by two outliers, one whose $\dot{\mathrm{V}}_{2 \max }$ was highly underestimated with the prediction equation, and one whose $\dot{\mathrm{V}}_{2 \max }$ was highly overestimated. Without these outliers, the SEE in $\mathrm{CV}_{2}$ was $338 \mathrm{~mL} \cdot \mathrm{min}^{-1}$, or $10.9 \%$. The overestimation was in a subject using $\beta_{2}$ agonists, but only as aerosols to treat chronic aspecific respiratory affection (CARA), which was unlikely to affect HR. The underestimation was in a subject who was very fit $(53.1 \mathrm{~mL}$. $\mathrm{kg}^{-1} \cdot \mathrm{min}^{-1}$ ) and able to generate a very high maximal HR (193 bpm) for his age (41 yr).

Regarding ease and convenience of the protocol, our fitness measure is very attractive for personal use as well as for research purposes. Because the monitors are worn during activities of daily life, no specific protocol is required. The accelerometer was developed to be unobtrusive in order not to interfere with normal life activity patterns. Given its small size and weight, it was not bothersome to any of the subjects. The HR monitor is sometimes more obtrusive when worn for longer periods, but most subjects enjoyed being able to monitor their own HR during different activities and considered it rather interesting and pleasant. Combining both the accelerometer and the HR monitor into one device would further improve wearing comfort.

Application for a broad population has to be evaluated on different considerations. The sample consisted of healthy, normal-weight and, on average, relatively fit subjects. Validity in study populations different from the one used in this study has yet to be investigated. As seen with $\mathrm{EXP}_{1}$ and $\mathrm{CV}_{1}$, differences in daily physical activity can influence the results. Therefore, the prediction equation 
has to be tested in populations that differ in physical activity and physical fitness from the current one, and population-specific equations might have to be developed. The major advantages, however, are that a specific protocol and maximal exertion are not needed, which makes it useful for subjects with low functional capacity. Therefore, it could be used in a variety of clinical settings, given that the equation has been validated in the population being studied. The total cost of a combined accelerometer/HR monitor should also be considered. In this study, population activity counts alone explained a substantial part of the variation in $\dot{\mathrm{VO}}_{2 \max }$, and thus the addition of HR monitoring to activity monitoring should be evaluated, depending on the research question. Likely, the inclusion of HR

\section{REFERENCES}

1. Astrand, P. O., and I. Ryhming. A nomogram for calculation of aerobic capacity (physical fitness) from pulse rate during submaximal work. J. Appl. Physiol. 7:218-221, 1954.

2. Bland, J. M., and D. G. Altman. Statistical methods for assessing agreement between two methods of clinical measurement. Lancet 1:307-310, 1986.

3. Bonen, A., V. H. Heyward, K. J. Cureton, R. A. Boileau, and B. H. MASSEy. Prediction of maximal oxygen uptake in boys, ages 7-15 years. Med. Sci. Sports 11:24-29, 1979.

4. CoOper, K. H. A means of assessing maximal oxygen intake. Correlation between field and treadmill testing. JAMA 203: 201-204, 1968.

5. Doolittle, T. L., and R. Bigbee. The twelve-minute run-walk: a test of cardiorespiratory fitness of adolescent boys. Res. Q. 39: 491-495, 1968.

6. Fox, E. L. A simple, accurate technique for predicting maximal aerobic power. J. Appl. Physiol. 35:914-916, 1973.

7. George, J. D., P. R. Vehrs, P. E. Allsen, G. W. Fellingham, and A. G. FISHER. Development of a submaximal treadmill jogging test for fit college-aged individuals. Med. Sci. Sports Exerc. 25: 643-647, 1993.

8. George, J. D., P. R. Vehrs, P. E. Allsen, G. W. Fellingham, and A. G. FISHER. $\mathrm{VO}_{2 \max }$ estimation from a submaximal 1-mile track jog for fit college-age individuals. Med. Sci. Sports Exerc. 25:401- 406, 1993.

9. Getchell, L. H., D. Kirkendall, and G. Robbins. Prediction of maximal oxygen uptake in young adult women joggers. Res. Q. 48: 61-67, 1977.

10. Jette, M., J. Campbell, J. Mongeon, and R. Routhier. The Canadian Home Fitness Test as a predictor for aerobic capacity. Can. Med. Assoc. J. 114:680-682, 1976.

11. Kline, G. M., J. P. Porcari, R.Hintermeister, et al. Estimation of $\dot{\mathrm{VO}}_{2 \max }$ from a one-mile track walk, gender, age, and body weight. Med. Sci. Sports Exerc. 19:253-259, 1987.

12. Kuipers, H., F. T. Verstappen, H. A. Keizer, P. Geurten, and G. VAN KRANENBURG. Variability of aerobic performance in the laboratory and its physiologic correlates. Int. J. Sports Med. 6:197-201, 1985. monitoring becomes essential when evaluating changes in physical fitness over time.

To our knowledge, this study marks the first attempt to develop a fitness index that does not require a specific protocol, can be used in daily life, is unobtrusive, and is sufficiently accurate. Care should be taken when applying the formula to subjects with a different activity pattern or activity level than was used in the present study. Further research should focus on testing the fitness index in larger and different study populations and on the ability to track changes in fitness over time. Further technical improvement, such as combining both monitors into one device, could improve wearing comfort and might result in even higher accuracy.

13. Leger, L., and R. Boucher. An indirect continuous running multistage field test: the Universite de Montreal track test. Can. J. Appl. Sport Sci. 5:77-84, 1980.

14. Leger, L. A., and J. Lambert. A maximal multistage 20-m shuttle run test to predict $\dot{\mathrm{VO}}_{2 \max }$. Eur. J. Appl. Physiol. Occup. Physiol. 49:1-12, 1982.

15. Leger, L. A., D. Mercier, C. Gadoury, and J. Lambert. The multistage 20 meter shuttle run test for aerobic fitness. J. Sports Sci. 6:93-101, 1988.

16. Lohman, T. G. Skinfolds and body density and their relation to body fatness: a review. Hum. Biol. 53:181-225, 1981.

17. MaKsud, M. G., and K. D. Coutrs. Application of the Cooper twelveminute run-walk test to young males. Res. Q. 42:54-59, 1971.

18. Margaria, R., P. Aghemo, and E. Rovelli. Indirect determination of maximal O2 consumption in man. J. Appl. Physiol. 20: 1070-1073, 1965.

19. Mastropaolo, J. A. Prediction of maximal O2 consumption in middle-aged men by multiple regression. Med. Sci. Sports 2: 124-127, 1970.

20. Naughton, L. M., D. Cooley, V. Kearney, and S. Smith. A comparison of two different shuttle run tests for the estimation of VO2max. J. Sports Med. Phys. Fitness 36:85-89, 1996.

21. Paliczka, V. J., A. K. Nichols, and C. A. Boreham. A multi-stage shuttle run as a predictor of running performance and maximal oxygen uptake in adults. Br. J. Sports Med. 21:163-165, 1987.

22. Plasqui, G., and K. R. Westerterp. Accelerometry and heart rate as a measure of physical fitness: proof of concept. Med. Sci. Sports Exerc. 37:872-876, 2005.

23. Treuth, M. S., K. Schmitz, D. J. Catellier, et al. Defining accelerometer thresholds for activity intensities in adolescent girls. Med. Sci. Sports Exerc. 36:1259-1266, 2004.

24. Weyand, P. G., M. Kelly, T. Blackadar, et al. Ambulatory estimates of maximal aerobic power from foot-ground contact times and heart rates in running humans. J. Appl. Physiol. 91:451-458, 2001.

25. Williams, P. T. Physical fitness and activity as separate heart disease risk factors: a meta-analysis. Med. Sci. Sports Exerc. 33:754-761, 2001. 